\title{
Artificial Solid Electrolyte Interphases for Lithium Metal Electrodes by Wet Processing: The Role of Metal Salt Concentration and Solvent Choice
}

\author{
Katharina Thanner, Alberto Varzi, Daniel Buchholz, Stefan J. Sedlmaier, and Stefano Passerini*
}

Cite This: ACS Appl. Mater. Interfaces 2020, 12, 32851-32862

Read Online

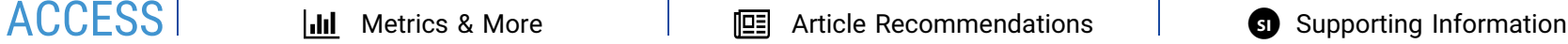

ABSTRACT: In this study, the artificial solid electrolyte interphase (SEI) formed on lithium metal when treated in $\mathrm{ZnCl}_{2}$ solutions is thoroughly investigated. The artificial SEI on lithium metal electrodes substantially decreases the interfacial resistance by ca. $80 \%$ and improves cycling stability in comparison to untreated lithium. The presence of a native SEI negatively affects the morphology and interfacial resistance of the artificial SEI. Increasing the $\mathrm{ZnCl}_{2}$ concentration in tetrahydrofuran (THF) (precursor solution) results in higher homogeneity of the surface morphology. Independent of the $\mathrm{ZnCl}_{2}$ concentrations, the artificial SEI is composed of $\mathrm{C}_{x}, \mathrm{CO}, \mathrm{LiCl}, \mathrm{Li}_{2} \mathrm{CO}_{3}, \mathrm{ZnCl}_{2}$, and $\mathrm{Li}_{x} \mathrm{Zn}_{y}$ alloys. $\mathrm{ZnCl}_{2}(1 \mathrm{M})$ produces the most homogenous surface

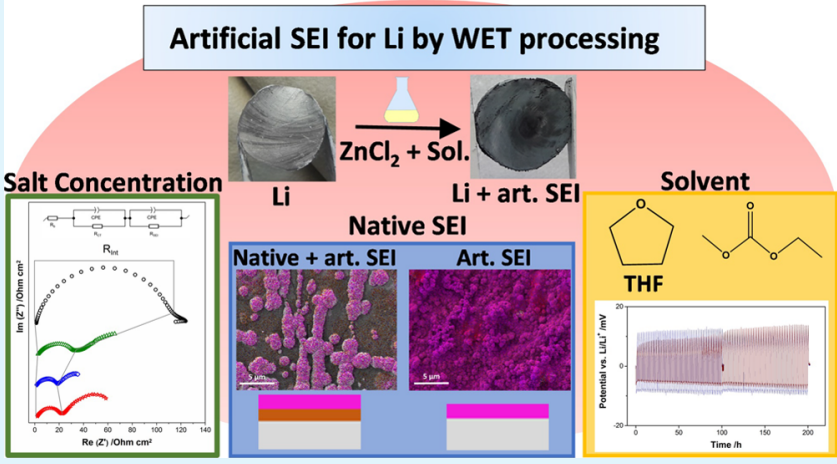
and additional surface species with carbonyl side groups. Nonetheless, the $\mathrm{ZnCl}_{2}$ concentration only has a small effect on the interfacial resistance or cycling stability. Using ethyl methyl carbonate (EMC) as the solvent significantly reduces the interfacial resistance to $7 \Omega \mathrm{cm}^{2}$, in comparison to $25 \Omega \mathrm{cm}{ }^{2}$ for THF. The composition of the artificial SEIs varies depending on the solvent. Either way, the SEI consists of $\mathrm{C}_{x} \mathrm{Li}_{x} \mathrm{C}, \mathrm{LiCl}_{2} \mathrm{Li}_{2} \mathrm{CO}_{3}, \mathrm{ZnCl}{ }_{2}$, and LiZn alloys. The THF-based SEI additionally features ether and carbonyl groups, $\mathrm{LiZnO}$, and $\mathrm{Zn}$ metal. For the artificial SEI formed with both solvents, the atomic percentage of the LiZn alloy increases close to the $\mathrm{Li}$ surface.

KEYWORDS: lithium metal battery, solid electrolyte interphase, artificial SEI, lithium alloys, SEI precursor, precursor solvent

\section{INTRODUCTION}

Nowadays, all-solid-state batteries are intensively investigated as they hold the promise of enabling improved cell performances and enhanced safety. The use of lithium metal as the anode is appealing to increase the battery cell energy and thereby to enable longer driving ranges due to the high theoretical volumetric and gravimetric capacities of lithium, $2062 \mathrm{~mA} \mathrm{~h} \mathrm{~cm}^{-3}$ and $3861 \mathrm{~mA} \mathrm{~h} \mathrm{~g}^{-1}$, respectively. ${ }^{1-3}$

The standard reduction potential of lithium $(-3.04 \mathrm{~V}$ vs standard hydrogen electrode, SHE) lies outside the electrolyte stability window of conventional liquid organic electrolytes. Consequently, the electrolyte is reduced by the lithium metal, leading to its decomposition and formation of a solid electrolyte interphase (SEI). ${ }^{4,5}$ If such an interphase does not possess sufficient mechanical stability and flexibility, the SEI will rupture because of the large volumetric changes of the electrode during cycling. In graphite electrodes, these volumetric changes can be up to $10 \%$, while for lithium metal electrodes, they are virtually infinite because of lithium being considered host-less. ${ }^{6}$ The continuous exposure of fresh lithium, as well as the rough surface of a damaged SEI, leads to inhomogeneous lithium plating during charging, resulting in significant reaction products between lithium and the liquid electrolyte (dead or mossy lithium) and eventually dendrite formation. These undesirable side reactions deteriorate the cell's life span, representing a serious safety hazard and preventing the commercialization of secondary lithium metal batteries with the liquid electrolyte. ${ }^{7}$

Since the 1980's, the SEI has been extensively studied, beginning with the pioneering work of Peled et al. and Aurbach et al. on the composition, physical, and electrochemical properties of the SEI formed in LIBs. ${ }^{8-11}$ The SEI was found to consist of a layer of microphases ranging from lithium oxide $\left(\mathrm{Li}_{2} \mathrm{O}\right)$ and lithium fluoride $(\mathrm{LiF})$ close to the electrode to lithium carbonates and polyolefin closer to the electrolyte. ${ }^{9}$ Such a layer is formed during the first charge as a result of electrolyte decomposition. The role of any SEI is to stabilize the anode surface and prevent side reactions with the

Received: May 15, 2020

Accepted: June 30, 2020

Published: June 30, 2020 
electrolyte and hence prolong the cell life. ${ }^{12}$ Therefore, it must possess a high lithium-ion conductivity while simultaneously being an electronic insulator. ${ }^{13}$ Additionally, the SEI must have sufficient mechanical stability and flexibility to withstand the volumetric changes of the anode upon charge and discharge also. ${ }^{6}$ So far, SEIs formed on graphite anodes in LIBs in combination with organic electrolytes fulfill the previously mentioned requirements, and the respective cells work well in commercialized products for various applications.

The disadvantage of SEIs formed during the formation cycle is the difficulty of precisely controlling the SEI composition. ${ }^{14}$ Stabilizing the anode surface prior to cycling via the targeted preparation of an SEI, a so-called artificial SEI, circumvents these issues and allows for greater control of the surface considering the composition, thickness, homogeneity, and conformity. Artificial SEIs formed on a graphite anode via electroplating or vacuum insertion of, for instance, carboxymethylcellulose were able to prolong the cycle life fivefold than those without prior treatment. ${ }^{15}$ Yet, to utilize the particularly high volumetric and gravimetric capacities of the lithium metal, an artificial SEI, specifically tailored for the lithium metal anode, is of great need.

So far, artificial SEIs on lithium metal anodes were often formed either by atomic-layer deposition, aeration, or coating in a liquid. ${ }^{16-18}$ The low-temperature atomic-layer deposition of $\mathrm{Al}_{2} \mathrm{O}_{3}$ on lithium showed improved stability toward ambient atmosphere, sulfidic solid electrolytes, and liquid electrolytes. However, the cell cycle life was still limited to 100 cycles. ${ }^{19}$ The direct reaction of lithium with nitrogen gas provided a relatively stable thin $\mathrm{Li}_{3} \mathrm{~N}$ film on the lithium surface, which allowed cycling for approximately 50 cycles before mossy dendrites were observed. ${ }^{20}$ Liang et al. showed promising results by stabilizing the lithium surface via the dip-coating process in a precursor solution consisting of a metal salt and an organic solvent, for instance, indium chloride $\left(\mathrm{InCl}_{2}\right)$ in tetrahydrofuran (THF). ${ }^{21}$ The authors suggest that the metal salt is reduced by the metallic lithium leading to the formation of a lithium metal alloy on the Li surface, which allowed for stable cycling at high currents for over $1000 \mathrm{~h}$. Zinc chloride $\left(\mathrm{ZnCl}_{2}\right)$ was also suggested as a potential metal salt, suitable for alloying with lithium, yet further in depth investigation was not provided.

Herein, we present the systematic development of an artificial SEI for lithium metal anodes by treatment in a zinc chloride $\left(\mathrm{ZnCl}_{2}\right)$ solution with different solvents and salt concentrations. To circumvent the influence of the native SEI, the artificial SEI in this study was directly formed on top of a pristine lithium surface, generated by cutting lithium metals directly in the precursor solution. ${ }^{22}$ The native SEI, consisting of inorganic species such as lithium hydroxide and lithium carbonate, is ever present on lithium metal because of its extremely high reactivity toward the surrounding atmosphere. $^{23}$ The native SEI can influence the composition of the artificial SEI and prevent the unambiguous assignment of electrochemical properties to the artificial SEI. Furthermore, the composition of the native SEI depends on the lithium provider and storage conditions and hence can vary from lithium batch-to-batch. As a control sample, pristine lithium is prepared by generating a fresh lithium surface in an inert atmosphere. Because the pristine lithium is prepared in a solvent-free argon-filled glove box (with $\mathrm{H}_{2} \mathrm{O}$ and $\mathrm{O}_{2} \leq 0.1$ $\mathrm{ppm}$ ), it is reasonably assumed to be native SEI-free. Hence, the influence of a native SEI on the properties of a lithium metal electrode can be avoided. Parameters such as metal salt concentration, precursor solvents, and the presence of a native SEI, affecting the morphology, interfacial resistance, and composition of the artificial SEI, were systematically investigated combining a multitude of analysis methods such as electrochemical impedance spectroscopy (EIS), galvanostatic cycling, scanning electron microscopy (SEM), X-ray spectroscopy (EDX), X-ray diffraction (XRD), and X-ray photoelectron spectroscopy (XPS). ${ }^{23}$

\section{RESULTS AND DISCUSSION}

2.1. Influence of the Native SEI on the Artificial SEI. To our knowledge, the explicit contribution of the native SEI on the artificial SEI on lithium has not yet been examined in detail. Therefore, this aspect was first investigated. Based on a previous work done by Liang et al., $\mathrm{ZnCl}_{2}$ in THF was chosen as a model precursor solution to understand the influence of the native SEI on the artificial one. ${ }^{21}$ Hence, the lithium metal was treated in $0.167 \mathrm{M} \mathrm{ZnCl}_{2}$ in THF via either dip coating (aSEI@nLi, artificial SEI on top of native Li surface) or cutting the metal directly in the precursor solution (aSEI@pLi, artificial SEI on top of a pristine Li surface). After drying the electrodes, the surface morphology of both samples was analyzed via SEM and EDX, as depicted in Figure 1.
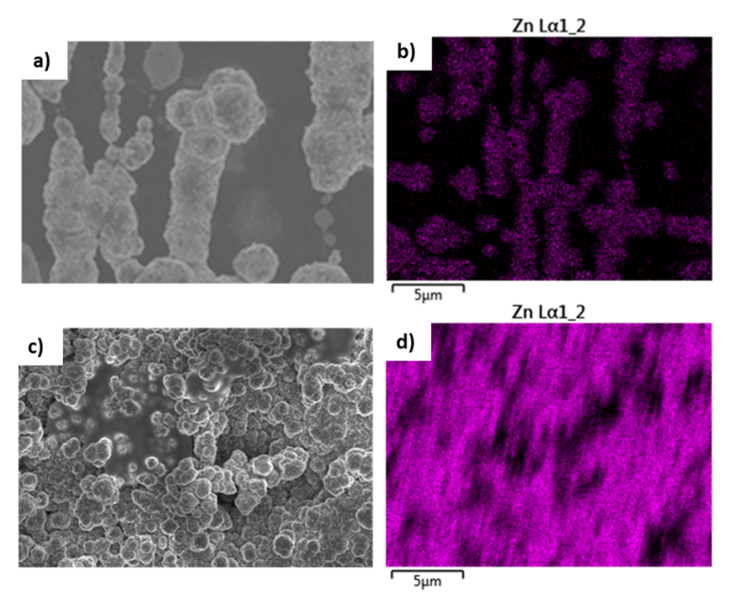

Figure 1. SEM images of $\mathrm{Li}$ coated with $0.167 \mathrm{M} \mathrm{ZnCl}_{2}$ in THF and the corresponding EDX spectra of zinc. Figures $a$ and $b$ show the surface of a $\mathrm{Li}$ sample with an artificial SEI formed on top of the native SEI (aSEI@nLi). In figures c and d, the surface was prepared with the artificial SEI on top of pristine lithium (aSEI@pLi).

The morphology and composition of the lithium surface vary significantly. In the presence of the native SEI, zinccontaining species agglomerate on the surface into rod-shaped clusters, which are not evenly distributed (Figure 1a,b). Differently, when the artificial SEI is formed directly on freshly cut lithium, defined particles $(\varnothing \mathrm{ca} .0 .5 \mu \mathrm{m})$ containing zinc are distributed uniformly on the surface (Figure 1c,d). This can be attributed to the passivating properties of the native SEI, lowering the reactivity of the lithium metal surface and resulting in the reduced homogeneity of the artificial SEI produced on top. Meyerson et al. analyzed in their work the surface composition of a native SEI facing the atmosphere and determined a mostly inorganic surface $\left(\mathrm{Li}_{2} \mathrm{O}\right.$ and $\left.\mathrm{Li}_{2} \mathrm{CO}_{3}\right)$ with organic-rich veins. ${ }^{24}$ The inorganic sections of the surface were shown to be less reactive than the organic-rich veins. The presence of these more reactive, organic-rich veins may explain 
the distribution of zinc in rod-shaped clusters. Beyond the agglomerates of zinc-containing particles, mostly oxygen and carbon were detected via EDX and displayed by mapping (Figure S1b,c). The detected oxygen and carbon can either derive from the native SEI or from the side reactions of lithium with the precursor solvent (THF). The carbon and oxygen EDX spectra also show a lack of the respective elements in the areas directly next to the rod-shaped agglomerates (Figure S1b,c, red circles), indicating the agglomerates to be raised, leading to the shadowing effect to be better visible, as shown in Figure S1.

In the carbon and oxygen spectra of aSEI@pLi, there are also areas with reduced amounts of carbon or oxygen (Figure $\mathrm{S} 1 \mathrm{e}, \mathrm{f}$, red circle). However, in these areas, a much lower zinc content was also detected (Figure 1d), suggesting that the shadowing effect of the surrounding topography prevented proper elemental mapping in the area. Aurbach et al. showed that the uniformity of the SEI morphology plays a determining role in its passivation effect. ${ }^{25}$ Therefore, because the higher homogeneity in the surface morphology as well as the option for the unambiguous assignment of electrochemical properties, all further tests were carried out on lithium metal electrodes without the presence of the native but only the artificial SEI (aSEI@pLi). Hence, all further work utilized the method of cutting lithium metal directly in the precursor solution.

2.2. Influence of Salt Concentrations on the Artificial SEI. 2.2.1. Morphology and Chemical Composition. The influence of individual factors of our model SEI precursor, such as the solvent choice and the salt concentration, on the artificial SEI has not yet been investigated in detail. As a first step, the influence of the metal salt concentration on the morphology and the composition of the artificial SEI was examined. Three precursor solutions were prepared at concentrations of $0.1,0.5$, and $1 \mathrm{M} \mathrm{ZnCl}_{2}$. THF as a solvent was kept as a constant, and all samples were prepared equally and analyzed via SEM (representative samples shown in Figure 2). $\mathrm{ZnCl}_{2}(1 \mathrm{M})$ was chosen as the highest concentration

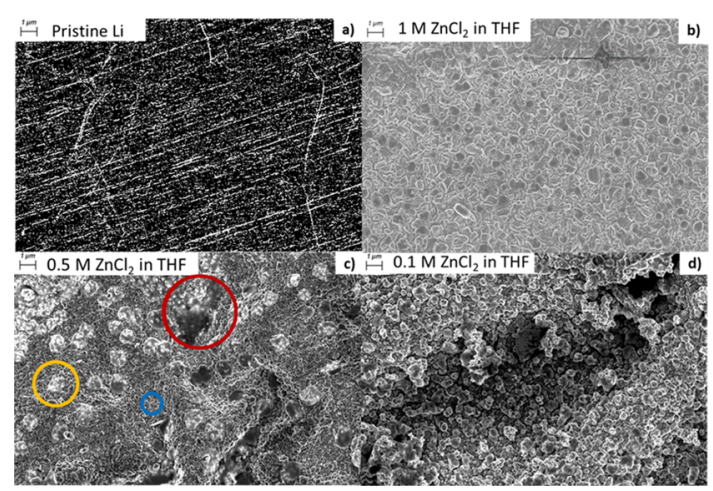

Figure 2. SEM images of (a) lithium pristine and coated with (b) $1 \mathrm{M}$ $\mathrm{ZnCl}_{2}$ in THF, (c) $0.5 \mathrm{M} \mathrm{ZnCl}_{2}$ in THF, and (d) $0.1 \mathrm{M} \mathrm{ZnCl}_{2}$ in THF.

because the solution already felt close to being saturated, and $\mathrm{ZnCl}_{2}$ would precipitate when the precursor solution was left unstirred. For these reasons, higher concentrations were excluded.

The SEM micrograph of the pristine lithium surface (Figure 2a) shows a smooth, homogenous surface with small, parallel, and linear indentations. These linear indentations result from the cutting process, as they correlate to the cutting direction of the tungsten wire and were not detectable once the surface was coated with an artificial SEI. No other relevant surface features are visible. Independent of the zinc chloride concentration, the protected surfaces show distinguishable particles varying in size from approximately $0.3-1 \mu \mathrm{m}$ (Figure $2 \mathrm{~b}, \mathrm{c}$ ). However, the surfaces noticeably differ in the morphology depending on the zinc chloride concentration. The $1 \mathrm{M} \mathrm{ZnCl}_{2}$ precursor solution results in a homogenous distribution of particles ranging in the size of ca. $0.5-1 \mu \mathrm{m}$ (Figure $2 \mathrm{~b}$ ). The particle layer itself is uniform and does not show any cracks or uncovered areas. In comparison, the surface produced by the $0.5 \mathrm{M} \mathrm{ZnCl}_{2}$ solution differs noticeably (Figure 2c). There are two types of particles visible, one has a diameter of approximately $1 \mu \mathrm{m}$ (yellow circle), while the other is much smaller with ca. $0.2 \mu \mathrm{m}$ (blue circle). The smaller particles cover almost the whole surface and contain zinc. The larger particles, not containing zinc, are not distributed uniformly across the surface (i.e., some areas do not show any particle, while in others, multiple particles are agglomerated together). Additionally, a small part of the surface is not covered by any particles (Figure 2c, red circle). EDX analyses of these smoother areas showed the presence of carbon but the lack of zinc and reduced amounts of oxygen (Figure S2, red circles). The $0.1 \mathrm{M} \mathrm{ZnCl}_{2}$ precursor solution establishes a surface covered in more similarly sized particles than the $0.5 \mathrm{M} \mathrm{ZnCl}_{2}$ solution (Figure $2 \mathrm{~d}$ ). The particles are all ca. $0.5 \mu \mathrm{m}$ large and cover entirely the surface, leaving no visible unprotected lithium. However, at this concentration, the artificial SEI does not seem to have a uniform thickness, considering the large crack spanning across the surface (Figure $2 \mathrm{~d}$ ). Although the crack itself is also covered in particles, it does reduce the conformity of the surface. Based on SEM imaging, a higher salt concentration results in a more homogeneous artificial SEI, both in the aspect of particle size distribution and surface conformity. Based on these morphological features, a solution with higher concentration seems the most promising for the establishment of an artificial SEI.

In order to get a deeper insight into the chemical composition of the artificial SEI, XPS analysis was carried out on lithium samples treated with THF solutions of different salt concentrations. The intensities of the spectra were normalized to account for intensity differences due to varying measurement parameters. However, because of background contributions, the normalized intensities cannot be taken as absolute values. Therefore, only the ratio of the atomic concentration of a chemical species, based on the peak areas, could be compared between different measurements. Still, clear distinctions were visible between the different concentrations in the $\mathrm{C} 1 \mathrm{~s}, \mathrm{Li} \mathrm{1s}, \mathrm{Cl} 2 \mathrm{p}$, and $\mathrm{Zn} 2 \mathrm{p}$ spectra (Figure 3). For all three concentrations, the $\mathrm{C} 1 \mathrm{~s}$ shows the $\mathrm{C}-\mathrm{C}$ and $\mathrm{C}-\mathrm{O}-\mathrm{C}$ group peaks at 285 and $286.4 \mathrm{eV}$, respectively (Figure 3a). For the artificial SEI based on $1 \mathrm{M} \mathrm{ZnCl}_{2}$ in THF, we see a third additional peak in the $\mathrm{C} 1 \mathrm{~s}$ spectrum, representing $\mathrm{C}=\mathrm{O}$ at a binding energy of $288.8 \mathrm{eV}$. The atomic concentration of the $\mathrm{C}-\mathrm{C}$ decreases with the increasing salt concentration from 92.5 to 88.5 , and $78.75 \%$ for $0.1,0.5$, and $1 \mathrm{M} \mathrm{ZnCl}_{2}$ concentrations, respectively. The atomic concentration of $\mathrm{C}-$ $\mathrm{O}-\mathrm{C}$ increases from 7.5 to $11.5 \%$ from 0.1 to $0.5 \mathrm{M} \mathrm{ZnCl}_{2}$ but decreases to $7.5 \%$ for $1 \mathrm{M} \mathrm{ZnCl}_{2}$ because of the presence of $14.0 \% \mathrm{C}=\mathrm{O}$. This shows that the composition of the artificial SEI is affected by the salt concentration in the precursor solution. At higher salt concentrations, the surface species increasingly contain $\mathrm{C}-\mathrm{O}-\mathrm{C}$ bonds and, eventually, carbonyl side groups. 


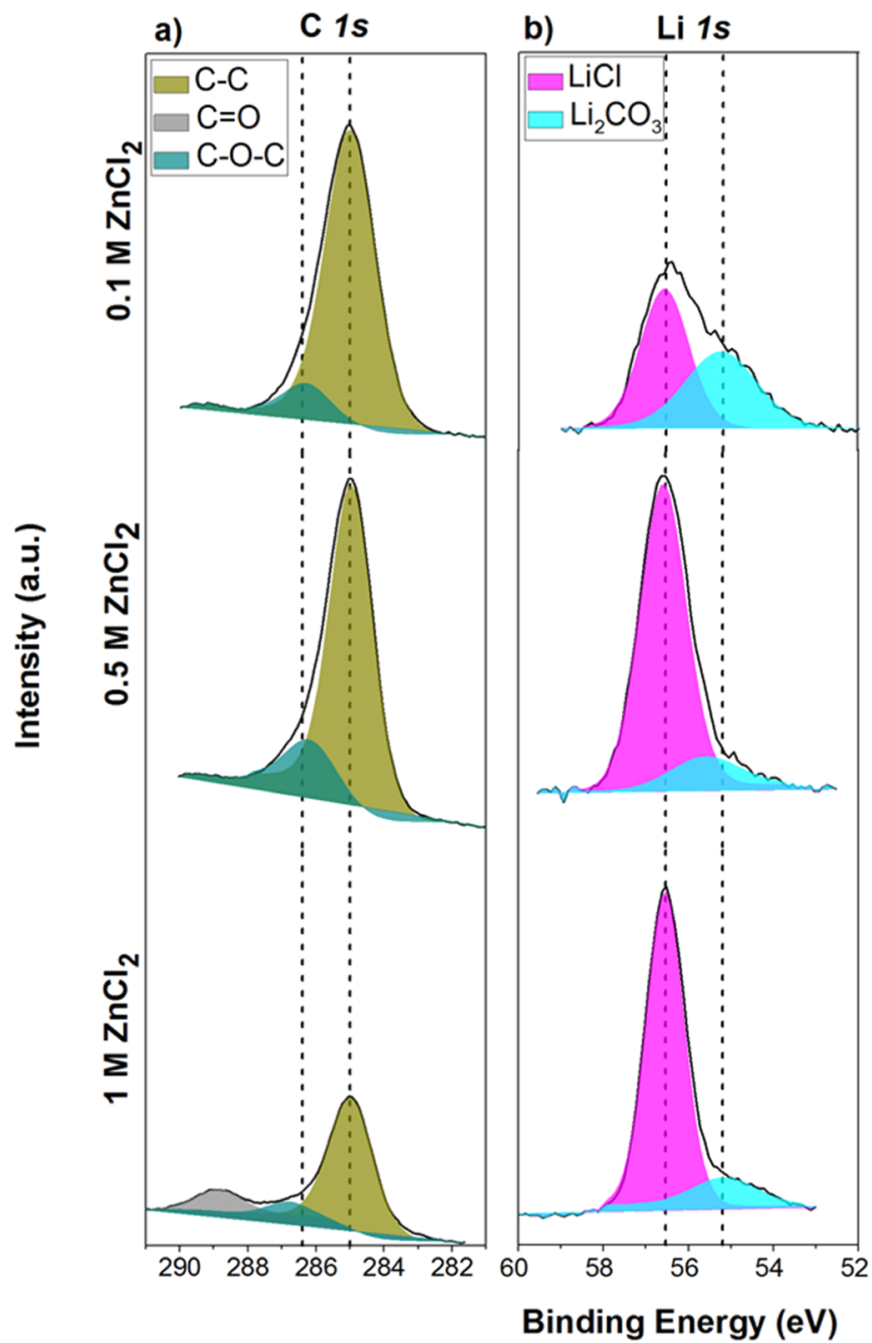

c)

$\mathrm{Zn} 2 p$

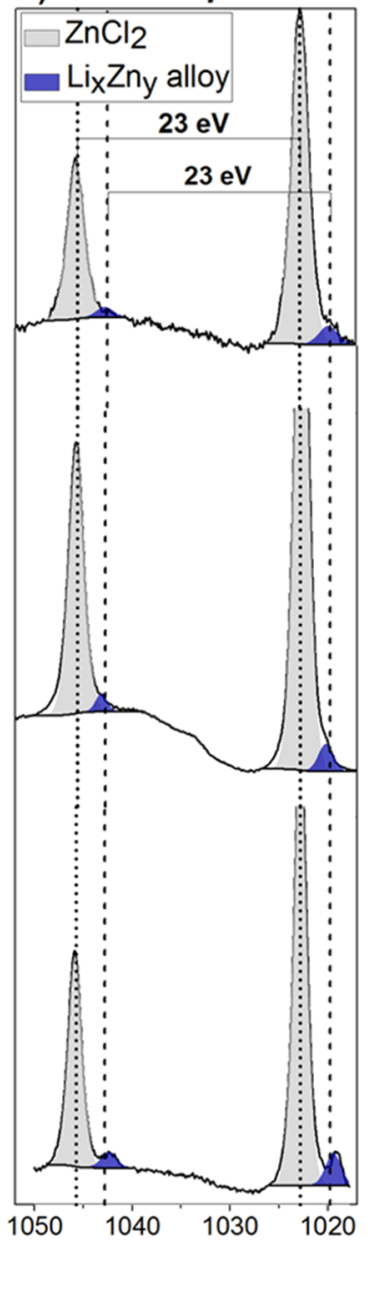

Figure 3. XPS analysis of protected lithium metal at $0.1,0.5$, and $1 \mathrm{M} \mathrm{ZnCl}_{2}$ in THF. (a) C 1s spectrum, (b) Li 1s spectrum, and (c) Zn 2p spectrum.

The $\mathrm{Li}$ 1s spectrum shows lithium carbonate and lithium chloride as main peaks at 55.12 and $56.5 \mathrm{eV}$, respectively (Figure $3 \mathrm{~b}$ ). For $0.1 \mathrm{M} \mathrm{ZnCl}_{2}$, the atomic ratio of $\mathrm{Li}_{2} \mathrm{CO}_{3}$ to $\mathrm{LiCl}$ is almost $1: 1$ at $45.0-55.0 \%$, respectively. At two higher salt concentrations, the atomic ratio of $\mathrm{Li}_{2} \mathrm{CO}_{3}$ to $\mathrm{LiCl}$ is almost identical with $12.0-88.0$ and $13.7-86.3 \%$.

Because $\mathrm{LiOH}$ and lithium metal have binding energies of 54.90 and $55.1 \mathrm{eV}$, respectively, their presence cannot be excluded completely. However, adding the $\mathrm{LiOH}$ peak would have degraded the quality of the overall spectral fit and was therefore excluded. The lithium metal was excluded on the fact that the SEM analysis of the SEI based on $1 \mathrm{M} \mathrm{ZnCl}_{2}$ in THF showed to have covered the lithium metal surface completely. Without any sputtering, it is unlikely to see any lithium metal on the artificial SEI surface at such a high metal salt concentration. The peak at $55.1 \mathrm{eV}$ is also not expected to represent the LiZn alloy. Although it was not possible to find any reference data in the literature, zinc has a higher electronegativity than lithium, and the alloy would therefore be expected at higher binding energies than the pure lithium metal. A similar trend was seen for the lithium-aluminum alloy. Metallic lithium is found at $54.1 \mathrm{eV}$, while the $\mathrm{LiAl}$ alloy is found at $55.4 \mathrm{eV}$. Because the electronegativity of aluminum and zinc is very similar, 1.61 and 1.65 , respectively, a similar shift is expected for the $\mathrm{LiZn}$ alloy. The $\mathrm{Cl} 2 \mathrm{p}$ spectrum (Figure S3) shows predominantly $\mathrm{ZnCl}_{2}$ and $\mathrm{LiCl}$. Correlating to the $\mathrm{Cl} 2 \mathrm{p}$ spectrum, the $\mathrm{Zn} 2 \mathrm{p}$ spectrum (Figure $3 \mathrm{c}$ ) shows the $\mathrm{ZnCl}_{2}$ doublet peak at 1022.8 and $1045.8 \mathrm{eV}$. The difference of $23 \mathrm{eV}$ in the binding energy and the peak area with a ratio of $2: 1$ prove the peaks being a doublet rather than two different species. The same can be said about the lithiumzinc (LiZn)-alloy doublet peak at 1019.5 and $1042.5 \mathrm{eV}$. The LiZn alloy can be found at slightly lower binding energies than metallic zinc, specifically at $1021.6 \mathrm{eV}$ (Figure S4). Lithium is more electropositive than zinc resulting in a reduction of binding energy of the alloy compound, as similarly seen during the XPS analysis of copper-zinc alloys by Deroubaix and Marcus. ${ }^{26}$ The lithium-zinc alloy does not have one distinctive peak position in the zinc spectrum, but the extent of the shift depends on the lithiation degree of zinc. A similar work done on lithium-aluminum alloys could confirm the presence of the alloy by a peak shift to lower binding energies. ${ }^{27}$ Interestingly, the atomic ratio of $\mathrm{ZnCl}_{2}$ to the $\mathrm{LiZn}$ alloy is almost identical for all three concentrations with 94.3-5.7, 95.6-4.4, and $92.8-7.2 \%$, respectively, going from the lowest to the highest concentration. However, with higher salt concentration, the $\mathrm{Li}-\mathrm{Zn}$-alloy peak becomes more pronounced, indicating a higher amount (in absolute terms) of LiZn alloy, as expected 
with higher salt concentration. Additionally to the changing LiZn-alloy content, the composition of the organic compounds found on the surface is affected. With the increasing $\mathrm{ZnCl}_{2}$ concentration, the ratio of $\mathrm{C}-\mathrm{O}-\mathrm{C}$ bonds increases, and carbonyl groups are additionally being formed.

To confirm the presence of a lithium-zinc alloy, XRD analysis of a samples treated with $0.1,0.5 \mathrm{M}$ (Figures S5 and S6), and $1 \mathrm{M} \mathrm{ZnCl}_{2}$ in THF (see Figure 4) was carried out.

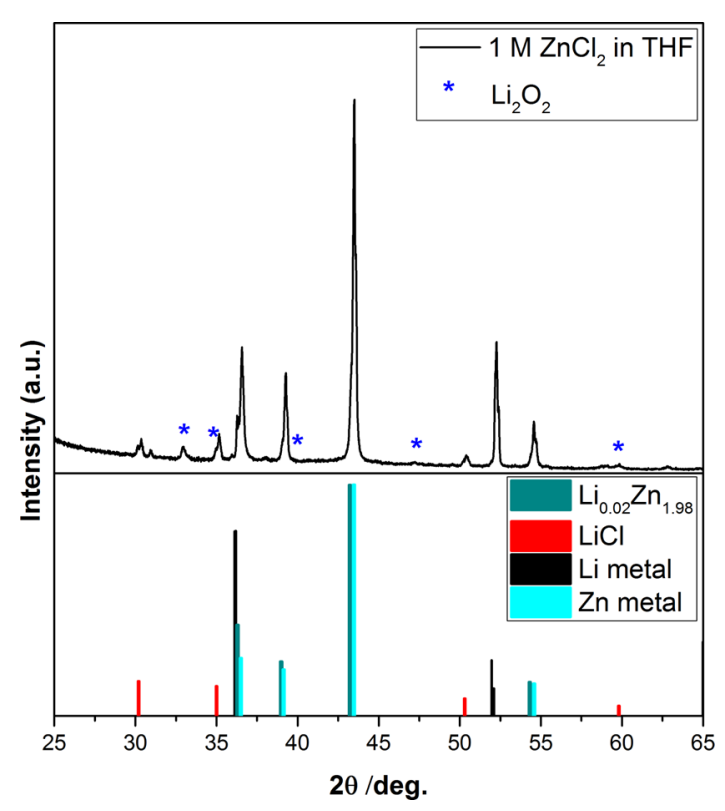

Figure 4. $\mathrm{XRD}$ pattern of $1 \mathrm{M} \mathrm{ZnCl}_{2}$ in THF-protected lithium metal. Data from the corresponding ICSD codes were used as reference: 181734 for zinc, 642408 for the $\mathrm{Li}_{0.02} \mathrm{Zn}_{1.98}$ alloy, 26909 for $\mathrm{LiCl}$, 25530 for $\mathrm{Li}_{2} \mathrm{O}_{2}$, and 151210 for $\mathrm{Li}$.

The main phases are consistent for all three concentrations, but the composition of the different artificial SEIs varies regarding reflections at low intensities, as seen in Figures S5 and S6.

For $1 \mathrm{M} \mathrm{ZnCl}_{2}$ in THF, the diffraction pattern shows the presence of crystalline phases, in accordance with the crystalline surface structure seen in the SEM image (Figure $2 \mathrm{~d}$ ). The reflections at $2 \theta=36^{\circ}$ and $2 \theta=52^{\circ}$ are attributed to the body-centered cubic structure of metallic lithium (space group $\operatorname{Im} \overline{3} m$ (no. 229), $a=3.500 \AA$ ). The XPS analysis showed the presence of $\mathrm{ZnCl}_{2}$; however, the corresponding reflections are absent in the XRD diffraction pattern. This could have two explanations; most likely, the $\mathrm{ZnCl}_{2}$ is present as a thin layer on top of the surface, too thin to be detectable by XRD, or $\mathrm{ZnCl}_{2}$ is amorphous and therefore not detectable. However, even a small contribution of an amorphous phase should still result in an increased background, which is noticeably absent in the above pattern. Hence the latter explanation is less likely. According to the literature, reflections at $2 \theta=30.17,35.17$, 50.38 , and $59.60^{\circ}$, fit the cubic structure of $\mathrm{LiCl}$ (space group $F \bar{m} m$ (no. 225 ); $a=2.5660 \AA$ ). Reflections with lower intensity such as at $2 \theta=32.8^{\circ}$ were attributed to the hexagonal structure of $\mathrm{Li}_{2} \mathrm{O}_{2}$ (space group $P 6_{3} / m m c$ (no. 194), $a=3.1420 \AA$, $c=$ $7.6500 \AA$ ) (Figure S7). It cannot be entirely excluded that the presence of $\mathrm{Li}_{2} \mathrm{O}_{2}$ may arise from impurities found either in anhydrous $\mathrm{ZnCl}_{2}$ or dried THF.

The distinction between metallic zinc and the lithium-zincalloy $\left(\mathrm{Li}_{0.02} \mathrm{Zn}_{1.98}\right)$ reflections is challenging because of a severe overlap of reflections (the unit cells of the alloy and metallic zinc are almost identical: space group $P 6_{3} / m m c$ (no. 194); zinc metal: $a=2.6700 \AA, c=4.9660 \AA$; LiZn alloy: $a=2.6655 \AA, c$ $=4.9467 \AA$ ). Reflections present at $2 \theta=36,39,43$, and $54^{\circ}$ can be attributed to both metallic zinc and the $\mathrm{Li}_{0.02} \mathrm{Zn}_{1.98}$ alloy (ICSD code 01-077-2883642408), especially, because the double peaks cannot be attributed to $\mathrm{Cu} \mathrm{K} \alpha$ radiation. In fact, the double peaks of $\mathrm{Cu} \mathrm{K} \alpha$ radiation always have the main peak at lower phase angles, which is not the case here. Surprisingly, neither the lithium-rich phase, LiZn, previously shown by Liang et al. nor any of the other many lithium-zincalloy phases could be detected. ${ }^{21}$ XRD shows clearly the decomposition of $\mathrm{ZnCl}_{2}$ into $\mathrm{LiCl}$ and potentially the $\mathrm{Zn}$ metal. The detection of $\mathrm{LiCl}$ by XRD confirms the XPS results. Because of the very similar reflection positions of the LiZn alloy and metallic zinc, it is not possible to completely differentiate between the two via XRD analysis. Even though metallic zinc was not detected via XPS on the electrode surface, the detected reflections shall most likely be attributed to the LiZn alloy and the $\mathrm{Zn}$ metal for the bulk of the electrode.

2.2.2. Electrochemical Behavior. In addition to the morphology, the influence of the salt concentration on the interfacial resistance of the lithium electrodes was investigated. Symmetric three-electrode EL cells were assembled and underwent an 8-day aging test at open-circuit conditions, including impedance measurements every $24 \mathrm{~h}$ at open-circuit voltage (OCV). The aging test followed 100 cycles of stripping and plating at a current of $0.1 \mathrm{~mA} \mathrm{~cm} \mathrm{~cm}^{-2}$ (Figure S9), intermitted and finished by another impedance measurement. The interfacial resistance $\left(R_{\text {Int }}\right)$ was calculated by adding the charge-transfer resistance $\left(R_{\mathrm{CT}}\right)$ and the resistance of the SEI $\left(R_{\mathrm{SEI}}\right)\left(R_{\mathrm{Int}}=R_{\mathrm{CT}}+R_{\mathrm{SEI}}\right)$. The equivalent circuit used for fitting the impedance data omitted the Warburg element because the interfacial resistance and not the diffusion was the focal point of this fit. The first ten cycles of stripping and plating are shown in Figure 5. To ensure the improvement in the electrochemical behavior is actually a result of $\mathrm{ZnCl}_{2}$; cells using pure THF as a precursor solution were also tested. As demonstrated in Figure S8, it is evident that THF alone is not capable of establishing an efficient artificial SEI.

The pristine lithium electrode shows an overvoltage of ca. $\pm 50 \mathrm{mV}$, approximately 1 order of magnitude higher than any of the samples protected by an artificial SEI (Figure 5a). This correlates with higher interfacial resistance shown in Figure 5e. Throughout the 100 cycles, the overpotential decreased to ca. $\pm 20 \mathrm{mV}$. The reduction in overpotential shows the modification of the passivation layer during the cycling process on the pristine lithium surface. The potential profile itself is asymmetric, and after the first three cycles, the electrode potential increases throughout each stripping step, showing higher polarization. A similar behavior can be seen for lithium protected by 0.5 and $1 \mathrm{M} \mathrm{ZnCl}_{2}$ in THF (Figure $5 \mathrm{c}, \mathrm{d}$ ). However, the lower overvoltage of ca. $\pm 10 \mathrm{mV}$ and the reduced polarization demonstrate the beneficial contribution of the protective layer. Additionally, the shape of the potential profiles was stable throughout the measured 100 cycles (Figure $\mathrm{S} 9 \mathrm{~b}, \mathrm{~d}, \mathrm{f})$. Interestingly, the most symmetric voltage profile is achieved by $0.1 \mathrm{M} \mathrm{ZnCl}_{2}$ in THF, ranging ca. $\pm 4 \mathrm{mV}$ (Figure $5 b)$. However, the shape of this voltage profile could also indicate a short circuit in the cell.

As seen in Figure 5e, the interfacial resistance is reduced significantly from ca. $110 \Omega \mathrm{cm}^{2}$ of pristine lithium to $15-25$ 

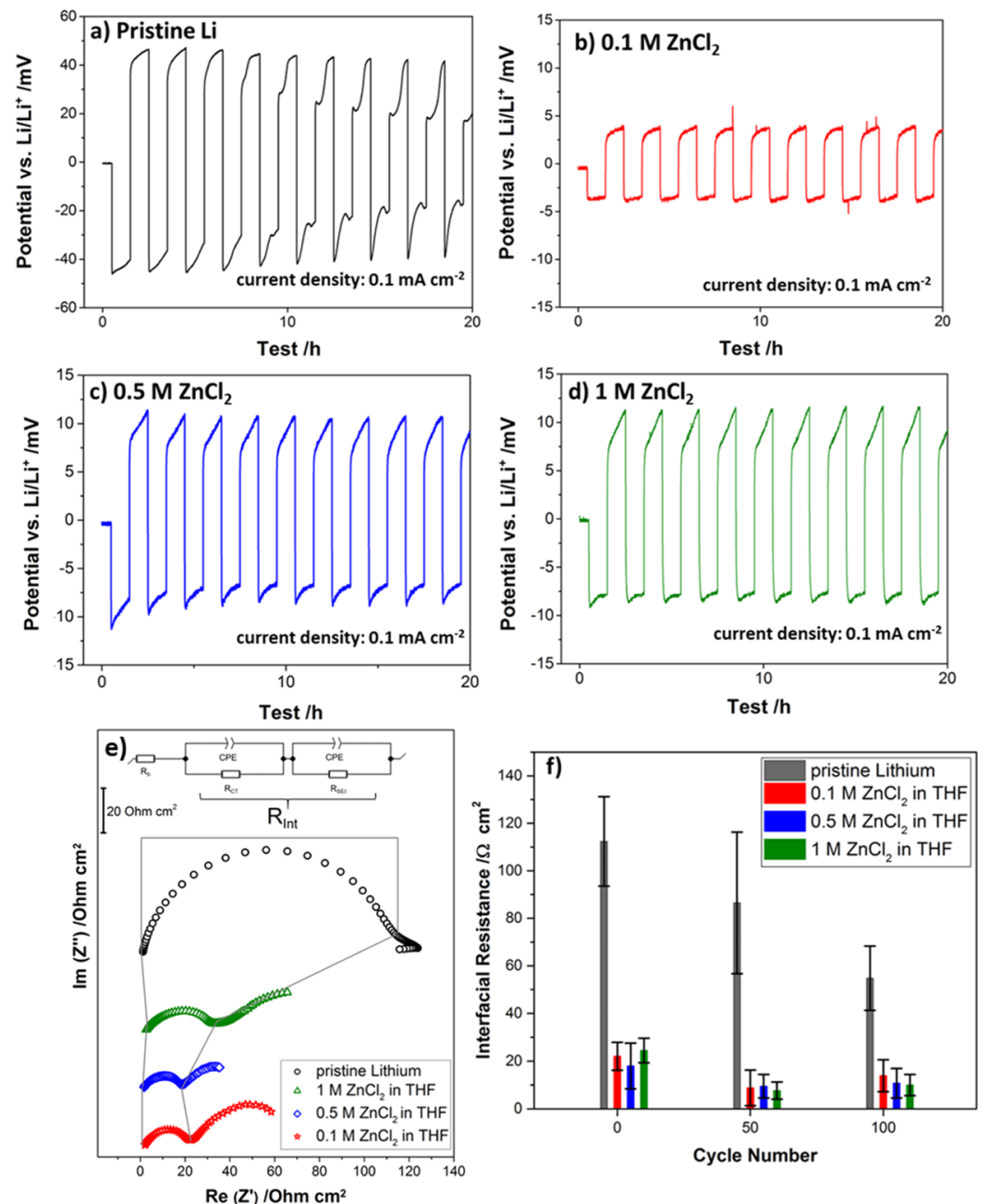

Figure 5. First 10 full stripping and plating cycles for (a) pristine lithium, (b) $0.1 \mathrm{M} \mathrm{ZnCl}_{2}$ in THF, (c) $0.5 \mathrm{M} \mathrm{ZnCl}_{2}$ in THF, and (d) $1 \mathrm{M} \mathrm{ZnCl}$ in THF: influence of the $\mathrm{ZnCl}_{2}$ concentration in THF on the interfacial resistance of the Li metal. The depicted electrical equivalent circuit was used for the fitting of the Nyquist plot shown in figure (e). The Nyquist plot shows the reduction in interfacial resistance $\left(R_{\mathrm{Int}}=R_{\mathrm{CT}}+R_{\mathrm{SEI}}\right)$ through the art. SEI, precycling on the 8th day of the aging test. Figure (f) shows the change in interfacial resistance after cycling the same cell for 50 and 100 cycles.

$\Omega \mathrm{cm}^{2}$ for protected lithium, for all investigated $\mathrm{ZnCl}_{2}$ concentrations. In all measurements, an increase in interfacial resistance during the 8-day aging test could be observed. This increase was significantly higher for the unprotected pristine lithium (approx. $90 \Omega \mathrm{cm}^{2}$ ) than for lithium with an artificial SEI (Figure S11). For the protected surfaces, the increase in interfacial resistance throughout the aging test was about $10 \Omega$ $\mathrm{cm}^{2}$. This shows that the lithium surface protected by an artificial SEI does reduce side reactions with the liquid electrolyte but cannot completely prevent them. Interestingly, after 50 cycles, the interfacial resistance in all cells with electrodes treated with the three precursor concentrations is almost identical at ca. $10 \Omega \mathrm{cm}^{2}$ (Figure 5f). After 100 cycles of stripping/plating, it increases minimally to around $12 \Omega \mathrm{cm}^{2}$ for all three concentrations. The relative stability of interfacial resistance upon cycling suggests that, as proposed by Liang et al., the deposition/stripping of lithium occurs underneath the artificial SEI. ${ }^{21}$ This avoids the direct contact of fresh lithium with the electrolyte. However, contrary to Liang et al., it was not possible to cycle any of the cells at higher current densities, such as $2 \mathrm{~mA} \mathrm{~cm}{ }^{-2}$. The initial reduction in interfacial resistance can be attributed to side reactions of lithium with the electrolyte, contributing to the surface passivation. After 100 cycles, the interfacial resistance is still less than one-third of that of unprotected lithium. The unprotected lithium experiences a significant reduction of the interfacial resistance from the approximate $120 \Omega \mathrm{cm}^{2}$ prior to cycling, to $90 \Omega \mathrm{cm}^{2}$ and finally ca. $60 \Omega \mathrm{cm}^{2}$, after 50 and 100 cycles, respectively. In this case, the significant, continuous reduction of the interface resistance can be explained by the reaction of the unprotected lithium surface with the electrolyte. The reaction products, such as $\mathrm{LiF}, \mathrm{Li}_{2} \mathrm{CO}_{3}$, and other organic compounds, passivate the surface and probably increase the overall surface area of the electrode, resulting in a reduction of the interfacial resistance. $^{28}$ Additionally, upon stripping, fresh lithium is exposed and consumed by further side reactions with the electrolyte, producing dead lithium on the surface. During plating, inhomogeneous lithium deposition leads to an increased surface area. The increased surface area contributes positively to the reaction rate at the lithium surface while it simultaneously reduces the polarization of the lithium metal anode at the electrolyte interface. ${ }^{29,30}$ Both effects cause a reduction of the interfacial resistance but are detrimental to the 


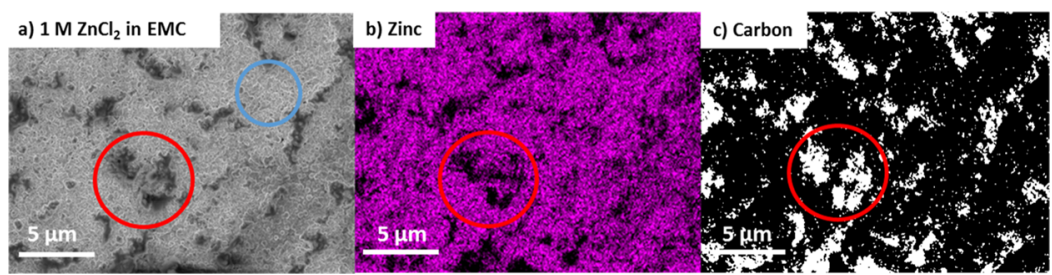

Figure 6. SEM images showing the surface of aSEI@EMC (a). Panels $(b, c)$ show the corresponding EDX spectra of zinc and carbon.

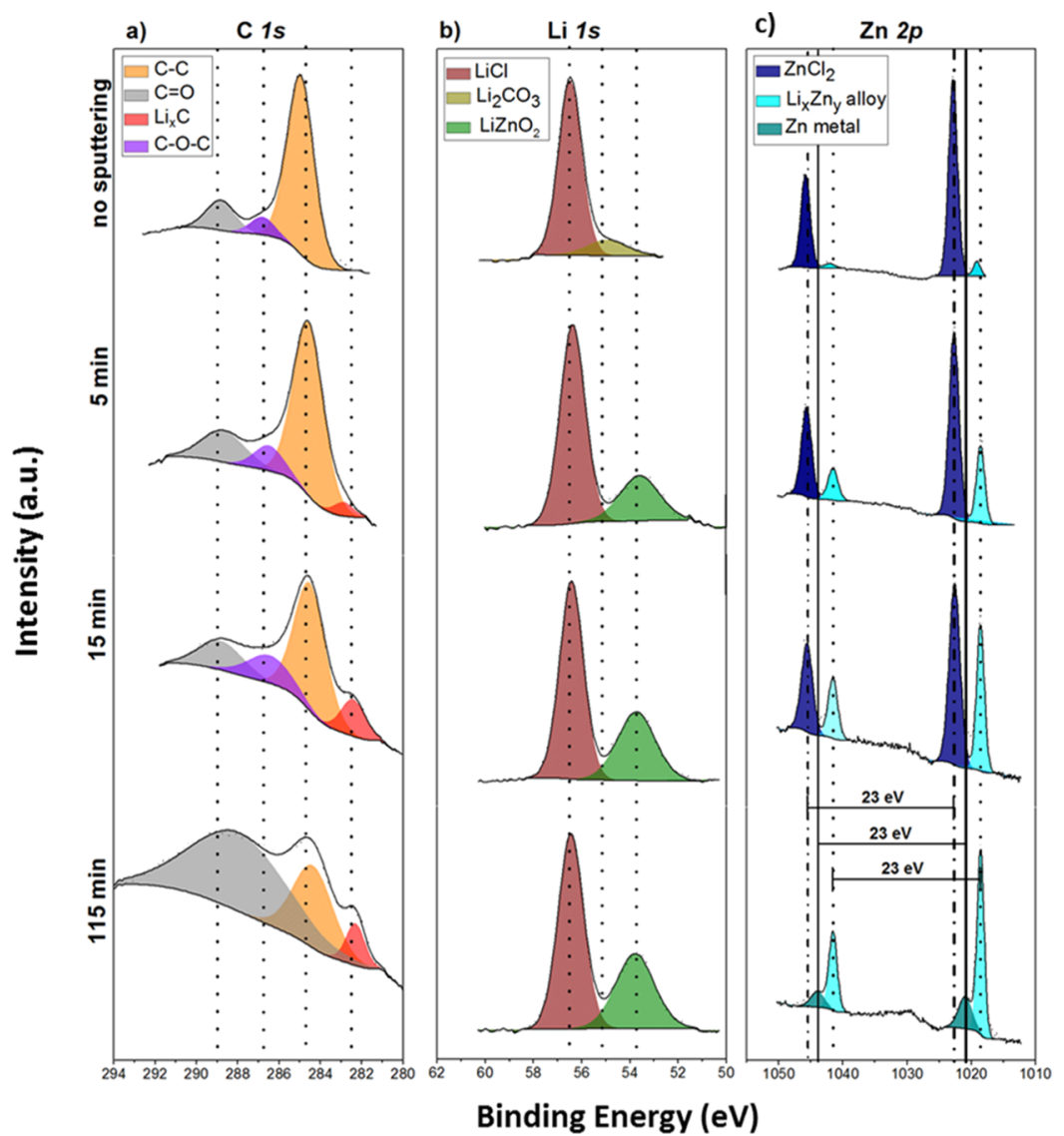

Figure 7. XPS analysis of lithium metal anodes, protected by $1 \mathrm{M} \mathrm{ZnCl}_{2}$ in THF. The sample was sputtered for $0,5,15$, and $115 \mathrm{~min}$. (a) C $1 \mathrm{~s}$ spectrum, (b) Li 1s spectrum, and (c) Zn 2p spectrum.

cycle life, either by depleting the lithium present in the anode or leading to dendrite formation.

2.3. Influence of the Precursor Solvent on the Artificial SEl. 2.3.1. Morphology, Chemical Composition, and In-Depth Profiling. In order to investigate the influence of the precursor solvent on the artificial SEI, $1 \mathrm{M} \mathrm{ZnCl}_{2}$ in THF (aSEI@THF) and $1 \mathrm{M} \mathrm{ZnCl} 2$ in ethyl methyl carbonate (EMC) (aSEI@EMC) were chosen as the model precursor solutions. All surfaces were prepared as mentioned above and analyzed via SEM and EDX. Results for aSEI@THF were shown previously in Figure 2, and the analysis of aSEI@EMC is shown in Figure 6.

As seen in Figures 2 and 6, the surface morphology varies significantly among the investigated samples. On the surface of aSEI@EMC (Figure 6a), it is more difficult to distinguish individual particles via SEM analysis. Instead, the surface clearly consists of two different areas. One area is composed of particles approximately $0.5 \mu \mathrm{m}$ in size (Figure 6a, blue circle). However, the individual particles are conglomerated and can barely be distinguished. The second area (Figure 6a, red circle) is not covered by particles or another distinguishable surface. Yet, this seemingly uncovered area does not show the same linear indentations as the pristine lithium surface.

Indeed, the EDX mapping of aSEI@EMC shows the zinc distribution on the surface, correlating well with the coverage by the conglomerated particles (Figure 6b). Areas without particles present also show lower zinc contributions but a high carbon content (Figure 6b,c, red circle). In areas in which zinc and consequently particles were mapped, barely any carbon contribution was detected. On the other hand, EDX mapping of aSEI@THF shows a homogenous distribution of zinc on the surface (Figure S10). This finding is in good agreement with the even distribution of particles on the surface seen via SEM analysis (Figure $2 b$ ). The differing zinc distribution on the surface shows that the choice of the solvent significantly influences the surface morphology.

The XPS analysis was performed on freshly coated electrodes, which were transferred to the instrument via an air-tight vessel. As explained before it was not possible to compare peak intensities between aSEI@THF and aSEI@ 

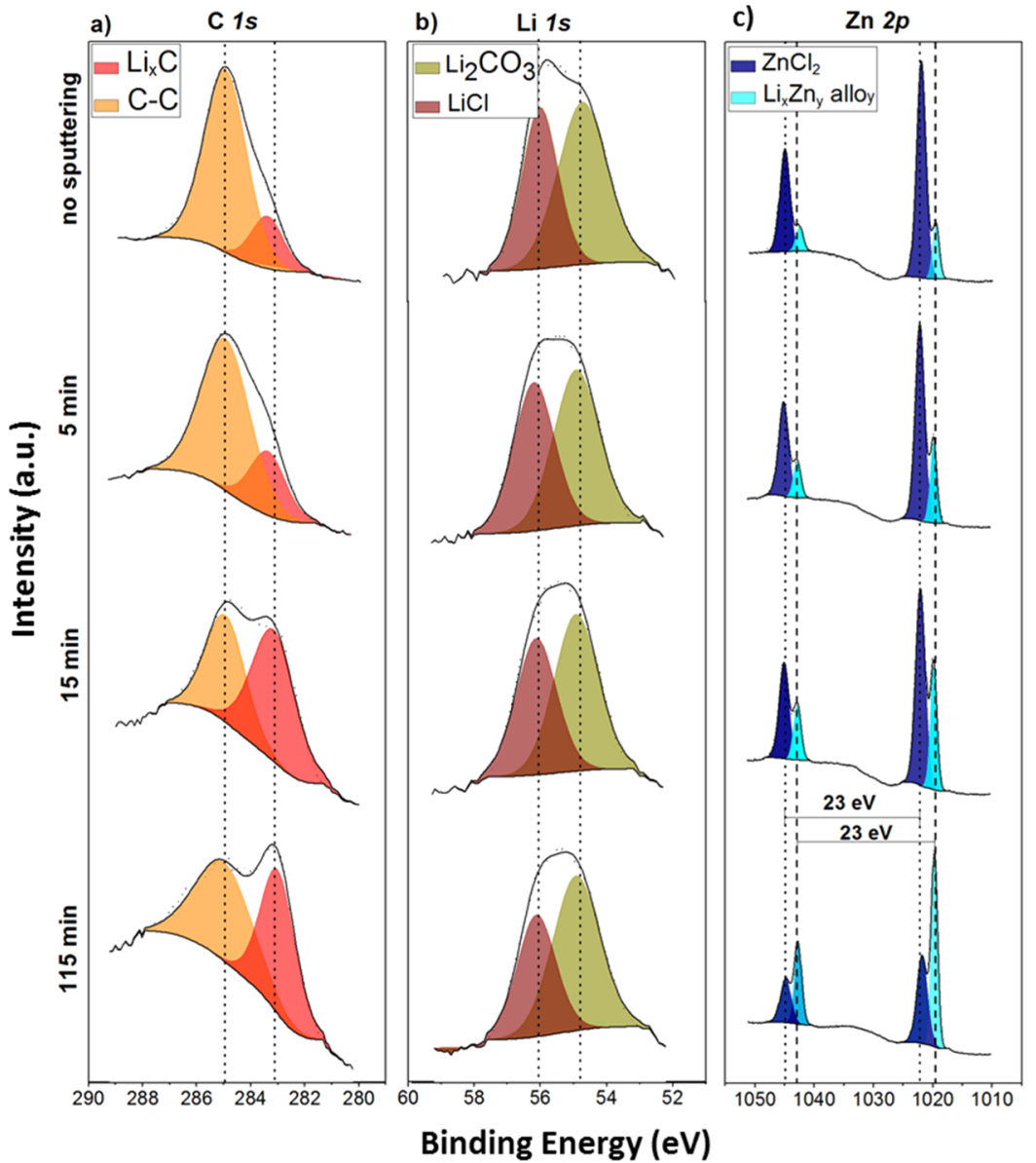

Figure 8. XPS analysis of a lithium metal electrode protected by $1 \mathrm{M} \mathrm{ZnCl}_{2}$ in EMC. The sample was sputtered for 0, 5, 15, and 115 min. (a) C 1s spectrum, (b) Li 1s spectrum, and (c) Zn 2p spectrum.

EMC; however, the change in the atomic concentration can be compared with one sputtered sample, as the measuring parameters remain the same. It is estimated that during the sputtering process, $0.6-1 \mathrm{~nm} / \mathrm{min}$ of the material is removed. The XPS analysis shows clear differences between the two investigated artificial SEIs, as displayed by the $\mathrm{C} 1 \mathrm{~s}, \mathrm{Li} 1 \mathrm{~s}, \mathrm{Cl}$ $2 \mathrm{p}$, and $\mathrm{Zn} 2 \mathrm{p}$ spectra reported in Figures 7 and 8.

Prior to sputtering, the C 1s spectrum aSEI@THF shows the characteristic peaks of $\mathrm{C}-\mathrm{C}, \mathrm{C}-\mathrm{O}-\mathrm{C}$, and $\mathrm{C}=\mathrm{O}$ at 285 , 286.4 , and $288.8 \mathrm{eV}$, respectively (Figure $7 \mathrm{a}$ ). Upon removal of 3-5 $\mathrm{nm}$ of the material ( 5 min sputtering), an additional peak appears at $282.4 \mathrm{eV}$, representing lithium intercalated into carbon. ${ }^{31}$ The atomic concentration of the carbon containing intercalated lithium increases upon further sputtering from 4 to $12 \%$, after $15 \mathrm{~min}$ of sputtering. However, after $115 \mathrm{~min}$ of sputtering (ca. 69-115 $\mathrm{nm}$ material removed), the atomic percentage reduces back down to $7 \%$. This is the first indicator of the artificial SEI being composed of a layered structure or made up of various microphases. The carbon layer containing intercalated lithium seems to have a minimum thickness of 66-112 nm. Even after $115 \mathrm{~min}$ of sputtering, there is still a $\mathrm{Li}_{x} \mathrm{C}$ peak present, and the layer thickness is most likely higher. Additionally, upon sputtering, the atomic concentration of CC decreased from 79\% (no sputtering) to 29\% (115 min sputtering). With the reduction of the $\mathrm{C}-\mathrm{C}$ atomic ratio, the share of $\mathrm{C}-\mathrm{O}-\mathrm{C}$ bonds and carbonyl groups increases. The concentration of the $\mathrm{C}-\mathrm{O}-\mathrm{C}$ bonds rises from 7 to $17 \%$ within the first $15 \mathrm{~min}$ of sputtering. After $115 \mathrm{~min}$ of sputtering, the $\mathrm{C}-\mathrm{O}-\mathrm{C}$ bond peak disappears; however, in this case, the peak of the carbonyl group is relatively broad and therefore could be covering the $\mathrm{C}-\mathrm{O}-\mathrm{C}$ bond peak. This would also explain the large increase in the atomic percentage from $14,17 \%$, and finally $65 \%$ after no, 15 , and $115 \mathrm{~min}$ of sputtering, respectively. However, there was no reasonable fit for adding an individual $\mathrm{C}-\mathrm{O}-\mathrm{C}$ bond peak in this spectrum. The $\mathrm{C} 1 \mathrm{~s}$ spectrum shows that the carbon composition changes throughout the artificial SEI, indicating a change in artificial SEI when approaching the lithium metal bulk.

The $\mathrm{Li} 1 \mathrm{~s}$ spectrum shows lithium chloride at $56.5 \mathrm{eV}$ (Figure $7 \mathrm{~b}$ ) as the main peak. Throughout the sputtering process, the atomic concentration of $\mathrm{LiCl}$ decreases from $86 \%$, via 74 and 64, to $63 \%$ for no, 5, 15, and 115 min sputtering, respectively. This shows that the $\mathrm{LiCl}$ concentration at the surface of the artificial SEI is significantly higher than in the bulk of the artificial SEI. The consistency in the atomic concentration after 15 and $115 \mathrm{~min}$ of sputtering indicates, however, that $\mathrm{LiCl}$ is present throughout the whole SEI and does not disappear closer to the lithium metal surface. Interestingly, $\mathrm{Li}_{2} \mathrm{CO}_{3}$ was only detected at $55.12 \mathrm{eV}$ prior to sputtering with an atomic concentration of $14 \%$. Instead, in all sputtered samples, $\mathrm{LiZnO}$ was detected at $53.7 \mathrm{eV}$. Its atomic concentration increases throughout sputtering from 26 to $37 \%$ after 5 and $15 \mathrm{~min}$ of sputtering, respectively. This once again shows that the chemical composition varies from the surface toward the bulk of the artificial SEI. 
The $\mathrm{Cl} 2 \mathrm{p}$ spectrum (Figure S12a) shows predominantly the $\mathrm{ZnCl}_{2}$ doublet at a binding energy of 198.8 and $200.4 \mathrm{eV}$. The $\mathrm{LiCl}$ doublet was detected at 199.6 and $201.2 \mathrm{eV}$. For once, the atomic concentrations of both $\mathrm{ZnCl}_{2}$ and $\mathrm{LiCl}$ remain relatively constant throughout the complete sputtering process. This may indicate that it was present in excess during the formation process of the artificial SEI. In correlation to the $\mathrm{Cl}$ $2 \mathrm{p}$ spectrum, the $\mathrm{Zn} 2 \mathrm{p}$ spectrum (Figure $7 \mathrm{c}$ ) shows the $\mathrm{ZnCl}_{2}$ doublet peak at 1022.8 and $1045.8 \mathrm{eV}$. The atomic percentage of $\mathrm{ZnCl}_{2}$ decreases upon sputtering from 63 and 49 to $42 \%$ for no, 5, and 15 min of sputtering, respectively. Interestingly, after 115 min of sputtering, contrary to the $\mathrm{Cl} 2 \mathrm{p}$ spectrum, there is no further detection of $\mathrm{ZnCl}_{2}$. Instead, at $1021.0 \mathrm{eV}$, the zinc metal occurred. This further supports $\mathrm{ZnCl}_{2}$ being present in an excess in the precursor. Toward the surface of the artificial SEI, more unreacted $\mathrm{ZnCl}_{2}$ is expected to be found, while the lithium metal would fully reduce $\mathrm{ZnCl}_{2}$ to the zinc metal closer to the lithium surface. With a binding energy of $1018.5 \mathrm{eV}$, the lithium zinc ( $\mathrm{LiZn}$ ) alloy can be found at slightly lower binding energies than metallic zinc. As explained previously, lithium has a higher electropositivity than zinc, resulting in a reduction of binding energy of the alloy compound. ${ }^{26,32}$ Interestingly, the LiZn-alloy atomic concentration increases significantly from 4 to $50 \%$ from no sputtering up to $115 \mathrm{~min}$. This shows that the majority of the LiZn alloy can be found close to the lithium metal surface.

The composition of aSEI@EMC shows some remarkable differences compared to the case of THF (Figure 8). In the C 1 s spectrum (Figure $8 \mathrm{a}$ ), only the $\mathrm{C}-\mathrm{C}$ peak at $285 \mathrm{eV}$ and the $\mathrm{Li}_{x} \mathrm{C}$ peak at $282.8 \mathrm{eV}$ can be appreciated. Interestingly, for this sample, the carbon with intercalated lithium was already detectable prior to sputtering. As before, its atomic concentration increases throughout the sputtering process from $18 \%$ prior to sputtering to $48 \%$ after $115 \mathrm{~min}$ of sputtering. Similarly, the $\mathrm{C}-\mathrm{C}$ atomic concentration decreases from initially $82 \%$ prior to sputtering to $52 \%$ after $115 \mathrm{~min}$ of sputtering. Even though EMC has more oxygen atoms per molecule than THF, it is interesting to see that neither the C$\mathrm{O}-\mathrm{C}$ bond nor carbonyl groups were detected. As before, the $\mathrm{Li} 1$ s spectrum (Figure $9 \mathrm{~b}$ ) shows the $\mathrm{LiCl}$ peak at $56.5 \mathrm{eV}$ and the $\mathrm{Li}_{2} \mathrm{CO}_{3}$ peak at $55.12 \mathrm{eV}$. Contrary to the aSEI@THF, aSEI@EMC does not show a LiZnO peak. Even upon sputtering, the only two species detected in the Li 1s spectrum are $\mathrm{LiCl}$ and $\mathrm{Li}_{2} \mathrm{CO}_{3}$. Throughout the sputtering process, the ratio of $\mathrm{LiCl}$ to $\mathrm{Li}_{2} \mathrm{CO}_{3}$ changes from $1: 1.35$ to $1: 1.60$, indicating an increase of $\mathrm{Li}_{2} \mathrm{CO}_{3}$ toward the lithium metal bulk.

The $\mathrm{Cl} 2 \mathrm{p}$ spectrum (Figure $\mathrm{S} 12 \mathrm{~b}$ ) shows only the $\mathrm{ZnCl}_{2}$ doublet at a binding energy of 198.8 and $200.4 \mathrm{eV}$. The $\mathrm{Zn} 2 \mathrm{p}$ spectra (Figure $8 \mathrm{c}$ ) correlate to the $\mathrm{Cl} 2 \mathrm{p}$ spectra by showing the $\mathrm{ZnCl}_{2}$ doublet peak at 1022.8 and $1045.8 \mathrm{eV}$. For this artificial SEI, the atomic percentage of $\mathrm{ZnCl}_{2}$ is reduced by almost half upon sputtering from 57 to $29 \%$ after $115 \mathrm{~min}$ of sputtering. In this sample, the zinc metal was not detected after any length of sputtering. Once again, the LiZn alloy was found at slightly lower binding energies of $1018.5 \mathrm{eV}$. Upon sputtering, the LiZn-alloy atomic concentration increases noticeable from 10 to $38 \%$ from no sputtering up to 115 min of sputtering. After $115 \mathrm{~min}$ of sputtering, the LiZn-alloy peak intensity and area are both larger than of $\mathrm{ZnCl}_{2}$. This shows that closer to the lithium surface, the majority of $\mathrm{ZnCl}_{2}$ in the precursor is forming the desired LiZn alloy.

2.3.2. Electrochemical Behavior. To investigate the influence of the solvent on the electrochemical behavior of
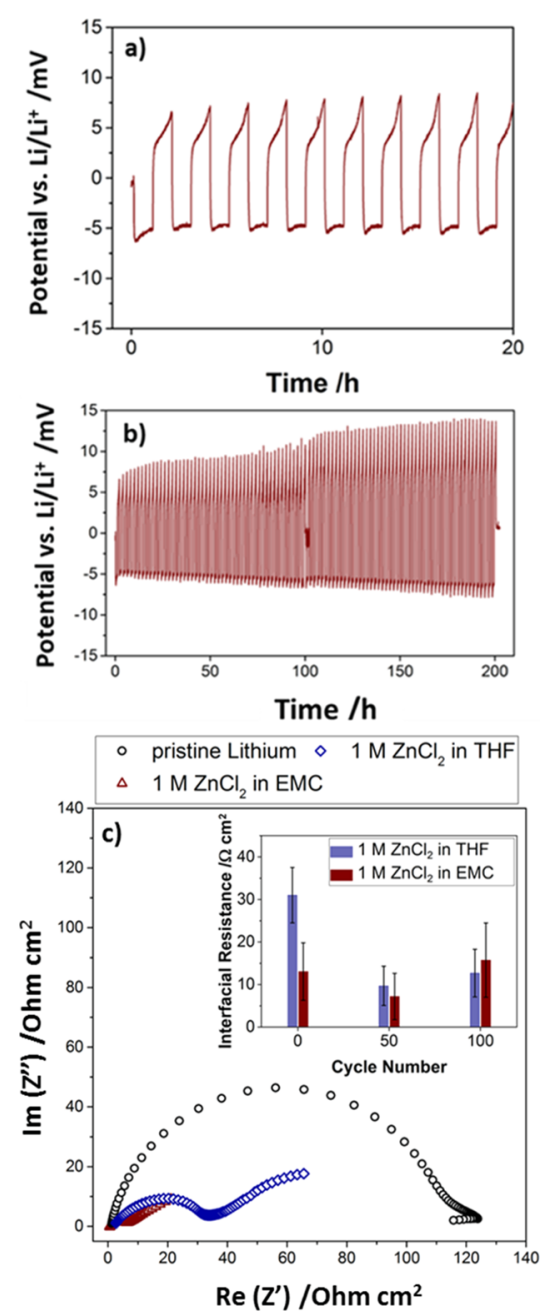

Figure 9. First 10 full stripping and plating cycles for (a) aSEI@EMC. In (b), complete cycling procedure is shown. Panel $c$ shows the influence of the solvent on the interfacial resistance. The electrical equivalent circuit shown in Figure 5 was used for fitting the highmedium frequency portion of the spectra in the Nyquist plot shown in figure (c). The Nyquist plot shows the reduction in interfacial resistance through the artificial SEI. The inset shows the change in interfacial resistance after cycling the same cell for 50 and 100 cycles.

the lithium metal, three-electrode symmetric EL-cells were assembled. Like before, the cells underwent an 8-day aging test, including impedance measurements every $24 \mathrm{~h}$ at OCV. Subsequently, 100 cycles of stripping and plating, intermitted and concluded by another impedance measurement, followed. In Figure 9a, the first ten cycles of stripping and plating are shown for aSEI@EMC.

Similarly, to aSEI@THF, the potential profile of aSEI@ EMC is asymmetric and shows an increasing polarization during each stripping step (Figures 9a and 5d). However, the aSEI@EMC electrode shows a lower overvoltage of ca. $\pm 7 \mathrm{mV}$ in comparison to ca. $\pm 10 \mathrm{mV}$ observed for aSEI@THF. Additionally, over the course of 100 cycles the overvoltage increases from ca. $7 \mathrm{mV}$ for aSEI@EMC to about $12 \mathrm{mV}$ for the stripping step (Figure 9b). The asymmetry of the voltage profile also increases throughout the cycling process. While the overvoltage in the stripping step increases significantly, it only decreases slightly in the plating step from -7 to $-8 \mathrm{mV}$. This behavior suggests that the surface layer may increase in thickness and/or become less conductive throughout the 
cycling process. In comparison, the overvoltage of aSEI@THF remains stable and only experiences a small dip after the cell was removed for the impedance measurement after 50 cycles (Figure S9g). The stability of voltage profile throughout cycling indicates a relatively stable artificial SEI.

As seen from the impedance spectra displayed in Figures $5 \mathrm{e}$ and 9c, both artificial SEIs reduce the interfacial resistance significantly from ca. $110 \Omega \mathrm{cm}^{2}$ for pristine lithium to ca. $25 \Omega$ $\mathrm{cm}^{2}$ and ca. $7 \Omega \mathrm{cm}^{2}$ for lithium protected with an aSEI@THF or aSEI@EMC, respectively. All cells showed an increase in interfacial resistance during the 8-day aging test. The largest increase was observed for pristine lithium (approx. $90 \Omega \mathrm{cm}^{2}$ ). In comparison, the interfacial resistance of aSEI@THF increased about $10 \Omega \mathrm{cm}^{2}$ and of aSEI@EMC only about 5 $\Omega \mathrm{cm}^{2}$ (Figure S13). This shows that independent of the solvent, the artificial SEI is beneficial in stabilizing the lithium surface and reduces unwanted side reactions with the liquid electrolyte. During the first 50 cycles, all cells experience a reduction in interfacial resistance. For the lithium metal protected by an artificial SEI, the change in interfacial resistance is much less than for pristine lithium, as seen in Figure 5f. For the cells using aSEI@THF, the interfacial resistance decreases from $25 \Omega \mathrm{cm}^{2}$ before cycling to around $10 \Omega \mathrm{cm}^{2}$ and increases again to $15 \Omega \mathrm{cm}^{2}$ after 50 and 100 cycles, respectively. A similar trend can be seen for cells containing aSEI@EMC. The interfacial resistance decreases during the first 50 cycles on average from $10 \Omega \mathrm{cm}^{2}$ to approximately $5 \Omega \mathrm{cm}^{2}$. In the last 50 cycles, the interfacial resistance increases back up to about $17 \Omega \mathrm{cm}^{2}$. The considerably smaller changes in the interfacial resistance than for pristine lithium show that independent of the solvent, both SEIs stabilize the lithium metal surface significantly. The increase in resistance during the second set of 50 cycles also indicates that the surface area is not increasing because of the exposure of fresh lithium. Therefore, as proposed by Liang et al., it is likely that the stripping and plating of lithium occurs underneath the artificial SEI. ${ }^{21}$ Yet, contrary to the proposal in their work, it was once again not possible to cycle at higher current densities than $0.1 \mathrm{~mA} \mathrm{~cm} \mathrm{~cm}^{2}$ because it immediately results in short circuit.

\section{CONCLUSIONS}

In summary, we have demonstrated that an artificial SEI based on $\mathrm{ZnCl}_{2}$ in THF reduces the interfacial resistance significantly. The presence of the native SEI beneath the artificial one negatively affects the morphology of the surface layer and zinc distribution. The $\mathrm{ZnCl}_{2}$ concentration in the precursor solution affects the morphology, with the highest concentration resulting in the most homogenous surface. However, the concentration has a negligible effect on the interfacial resistance. Interestingly, XPS analysis showed that the concentration does affect the surface composition. At high salt concentrations generally a higher amount of organic compounds could be detected, including species containing carbonyl groups. For all salt concentrations, the formation of a lithium-zinc alloy was suggested by XPS. Nonetheless, the presence of the lithium-zinc alloy could not be confirmed definitively via XRD. Further measurements are still required to fully clarify this point. Additionally, it was shown that the precursor solvent has a considerable influence on the artificial SEI. aSEI@THF provides a more homogenous surface, a more even zinc distribution, and slightly more symmetric voltage profile during cycling than aSEI@EMC. However, aSEI@EMC results in a lower interfacial resistance. The composition of the artificial SEIs is influence by the decomposition products of the precursor solvent. ${ }^{33,34}$ Both cases contain $\mathrm{C}_{x} \mathrm{Li}_{x} \mathrm{C}, \mathrm{LiCl}$, $\mathrm{Li}_{2} \mathrm{CO}_{3}, \mathrm{ZnCl}_{2}$, and $\mathrm{LiZn}$ alloys. The THF-based SEI additionally features $\mathrm{C}-\mathrm{O}-\mathrm{C}$ bonds and carbonyl groups, $\mathrm{LiZnO}$, and $\mathrm{Zn}$ metal. For both artificial SEIs, the atomic percentage of the $\mathrm{LiZn}$ alloy increases while the $\mathrm{ZnCl}_{2}$ concentration decreases. For aSEI@EMC, even after 115 min of sputtering, $\mathrm{ZnCl}_{2}$ was still detected, while for aSEI@ THF, this was not the case. Instead, the zinc metal was detected.

\section{EXPERIMENTAL SECTION}

Experimental details are discussed in Section 1 of the Supporting Information.

\section{ASSOCIATED CONTENT}

\section{Supporting Information}

The Supporting Information is available free of charge at https://pubs.acs.org/doi/10.1021/acsami.0c08938.

Experimental details regarding the preparation of the lithium metal with an artificial SEI and the consequent electrochemical and surface characterization; zinc, carbon, and oxygen EDX spectra of an artificial SEI based on $0.167 \mathrm{M} \mathrm{ZnCl}_{2}$ in THF on native SEI and pristine lithium; zinc, carbon, and oxygen EDX spectra of an artificial SEI based on $0.5 \mathrm{M} \mathrm{ZnCl}_{2}$ in THF; zinc EDX spectra of $1 \mathrm{M} \mathrm{ZnCl}_{2}$ in THF on pristine lithium; $\mathrm{Cl} 2 \mathrm{p}$ and $\mathrm{Zn} 2 \mathrm{p}$ XPS spectra of the artificial SEI with $0.1,0.5$, and $1 \mathrm{M} \mathrm{ZnCl}_{2}$ in THF; XRD diffraction pattern of $0.1,0.5$, and $1 \mathrm{M} \mathrm{ZnCl}_{2}$ in THF protected lithium; potential profile and Nyquist plot for $\mathrm{Li} / \mathrm{Li}$ symmetric cells protected by pure THF; potential profiles of $\mathrm{Li} / \mathrm{Li}$ symmetric cells protected with $0.1,0.5$, and $1 \mathrm{M} \mathrm{ZnCl}_{2}$ in THF; Nyquist plot of the first and last day of the aging test for pristine lithium, $0.1,0.5$, and $1 \mathrm{M} \mathrm{ZnCl}_{2}$ in THF; Cl 2p XPS spectra of the artificial SEI based on 1 $\mathrm{M} \mathrm{ZnCl}_{2}$ in THF and $1 \mathrm{M} \mathrm{ZnCl}_{2}$ in EMC; and Nyquist plot of the first and last day of the aging test for pristine lithium, $1 \mathrm{M} \mathrm{ZnCl}_{2}$ in THF, and $1 \mathrm{M} \mathrm{ZnCl}_{2}$ in $\mathrm{EMC}$ (PDF)

\section{AUTHOR INFORMATION}

\section{Corresponding Author}

Stefano Passerini - Helmholtz Institute Ulm (HIU), 89081

Ulm, Germany; Karlsruhe Institute of Technology (KIT),

76021 Karlsruhe, Germany; 이이.org/0000-0002-6606-

5304; Email: stefano.passerini@kit.edu

\section{Authors}

Katharina Thanner - Helmholtz Institute Ulm (HIU), 89081 Ulm, Germany; Karlsruhe Institute of Technology (KIT), 76021 Karlsruhe, Germany; BMW Group, 80788 München, Germany

Alberto Varzi - Helmholtz Institute Ulm (HIU), $89081 \mathrm{Ulm}$, Germany; Karlsruhe Institute of Technology (KIT), 76021

Karlsruhe, Germany; 이이.org/0000-0001-5069-0589

Daniel Buchholz - BMW Group, 80788 München, Germany

Stefan J. Sedlmaier - BMW Group, 80788 München, Germany

Complete contact information is available at:

https://pubs.acs.org/10.1021/acsami.0c08938 


\section{Author Contributions}

The manuscript was written through contributions of all authors. All authors have given approval to the final version of the manuscript.

\section{Notes}

The authors declare no competing financial interest.

\section{ACKNOWLEDGMENTS}

The HIU authors thank the BMW AG for the financial support of this work and the basic funding of the Helmholtz Association.

\section{ABBREVIATIONS}

SEI, solid electrolyte interphase

aSEI@nLi, artificial SEI on top of native Li surface aSEI@pLi, artificial SEI on top of a pristine Li surface $R_{\text {Int }}$ interfacial resistance

$R_{\mathrm{CT}}$, charge transfer resistance

$R_{\mathrm{SEI}}$, resistance of the SEI

aSEI@THF, artificial SEI based on $1 \mathrm{M} \mathrm{ZnCl}$ aSEI@EMC, artificial SEI based on $1 \mathrm{M} \mathrm{ZnCl}_{2}$ in EMC

\section{REFERENCES}

(1) Andre, D.; Hain, H.; Lamp, P.; Maglia, F.; Stiaszny, B. Future High-Energy Density Anode Materials from an Automotive Application Perspective. J. Mater. Chem. A 2017, 5, 17174-17198.

(2) Xu, W.; Wang, J.; Ding, F.; Chen, X.; Nasybulin, E.; Zhang, Y.; Zhang, J.-G. Lithium Metal Anodes for Rechargeable Batteries. Energy Environ. Sci. 2014, 7, 513-537.

(3) Lin, D.; Liu, Y.; Cui, Y. Reviving the Lithium Metal Anode for High-Energy Batteries. Nat. Nanotechnol. 2017, 12, 194-206.

(4) Tarascon, J.-M.; Armand, M. Nature Lithium Battery. Nature 2001, 414, 359-367.

(5) Cohen, Y. S.; Cohen, Y.; Aurbach, D. Micromorphological Studies of Lithium Electrodes in Alkyl Carbonate Solutions using In Situ Atomic Force Microscopy. J. Phys. Chem. B 2000, 104, 1228212291.

(6) Zheng, G.; Lee, S. W.; Liang, Z.; Lee, H.-W.; Yan, K.; Yao, H.; Wang, H.; Li, W.; Chu, S.; Cui, Y. Interconnected Hollow Carbon Nanospheres for Stable Lithium Metal Anodes. Nat. Nanotechnol. 2014, 9, 618-623.

(7) Brandt, K. Historical Development of Secondary Lithium Batteries. Solid State Ionics 1994, 69, 173-183.

(8) Peled, E. The Electrochemical Behavior of Alkali and Alkaline Earth Metals in Nonaqueous Battery Systems-The Solid Electrolyte Interphase Model. J. Electrochem. Soc. 1979, 126, 2047.

(9) Peled, E.; Golodnitsky, D.; Ardel, G. Advanced Model for Solid Electrolyte Interphase Electrodes in Liquid and Polymer Electrolytes. J. Electrochem. Soc. 1997, 144, L208.

(10) Aurbach, D.; Ein-Ely, Y.; Zaban, A. The Surface Chemistry of Lithium Electrodes in Alkyl Carbonate Solutions. J. Electrochem. Soc. 1994, 141, L1.

(11) Aurbach, D.; Daroux, M. L.; Faguy, P. W.; Yeager, E. Identification of Surface Films Formed on Lithium in Propylene Carbonate Solutions. J. Electrochem. Soc. 1987, 134, 1611.

(12) Verma, P.; Maire, P.; Novák, P. A Review of the Features and Analyses of the Solid Electrolyte Interphase in Li-Ion Batteries. Electrochim. Acta 2010, 55, 6332-6341.

(13) Liu, Y.; Lin, D.; Yuen, P. Y.; Liu, K.; Xie, J.; Dauskardt, R. H.; Cui, Y. An Artificial Solid Electrolyte Interphase with High Li-Ion Conductivity, Mechanical Strength, and Flexibility for Stable Lithium Metal Anodes. Adv. Mater. 2017, 29, 1605531.

(14) Zhu, Z.; Chen, X. Artificial Interphase Engineering of Electrode Materials to Improve the Overall Performance of Lithium-Ion Batteries. Nano Res. 2017, 10, 4115-4138.
(15) Menkin, S.; Golodnitsky, D.; Peled, E. Artificial SolidElectrolyte Interphase (SEI) for Improved Cycleability and Safety of Lithium-Ion Cells for EV Applications. Electrochem. Commun. 2009, 11, 1789-1791.

(16) Wang, H.-Y.; Wang, F.-M. Electrochemical Investigation of an Artificial Solid Electrolyte Interface for Improving the Cycle-Ability of Lithium Ion Batteries using an Atomic Layer Deposition on a Graphite Electrode. J. Power Sources 2013, 233, 1-5.

(17) Li, W.-j.; Li, Q.; Huang, J.; Peng, J.-Y.; Chu, G.; Lu, Y.-X.; Zheng, J.-Y.; Li, H. Gas Treatment Protection of Metallic Lithium Anode. Chin. Phys. B 2017, 26, 088202.

(18) Thompson, R. S.; Schroeder, D. J.; López, C. M.; Neuhold, S.; Vaughey, J. T. Stabilization of Lithium Metal Anodes using SilaneBased Coatings. Electrochem. Commun. 2011, 13, 1369-1372.

(19) Kozen, A. C.; Lin, C.-F.; Pearse, A. J.; Schroeder, M. A.; Han, X.; Hu, L.; Lee, S.-B.; Rubloff, G. W.; Noked, M. Next-Generation Lithium Metal Anode Engineering via Atomic Layer Deposition. ACS Nano 2015, 9, 5884-5892.

(20) Zhang, Y. J.; Wang, W.; Tang, H.; Bai, W. Q.; Ge, X.; Wang, X. L.; Gu, C. D.; Tu, J. P. An Ex-Situ Nitridation Route to Synthesize Li3N-Modified Li Anodes for Lithium Secondary Batteries. J. Power Sources 2015, 277, 304-311.

(21) Liang, X.; Pang, Q.; Kochetkov, I. R.; Sempere, M. S.; Huang, H.; Sun, X.; Nazar, L. F. A Facile Surface Chemistry Route to a Stabilized Lithium Metal Anode. Nat. Energy 2017, 2, 17119.

(22) Ding, M. S.; Koch, S. L.; Passerini, S. The Effect of 1Pentylamine as Solid Electrolyte Interphase Precursor on Lithium Metal Anodes. Electrochim. Acta 2017, 240, 408-414.

(23) David, D. J.; Froning, M. H.; Wittberg, T. N.; Moddeman, W. E. Surface Reactions of Lithium with the Environment. Appl. Surf. Sci. 1981, 7, 185-195.

(24) Meyerson, M. L.; Sheavly, J. K.; Dolocan, A.; Griffin, M. P.; Pandit, A. H.; Rodriguez, R.; Stephens, R. M.; Vanden Bout, D. A.; Heller, A.; Mullins, C. B. The Effect of Local Lithium Surface Chemistry and Topography on Solid Electrolyte Interphase Composition and Dendrite Nucleation. J. Mater. Chem. A 2019, 7, 14882-14894.

(25) Aurbach, D.; Zaban, A.; Gofer, Y.; Ely, Y. E.; Weissman, I.; Chusid, O.; Abramson, O. Recent Studies of the Lithium-Liquid Electrolyte Interface Electrochemical, Morphological and Spectral Studies of a Few Important Systems. J. Power Sources 1995, 54, 7684.

(26) Deroubaix, G.; Marcus, P. X-Ray Photoelectron Spectroscopy Analysis of Copper and Zinc Oxides and Sulphides. Surf. Interface Anal. 1992, 18, 39-46.

(27) Qin, B.; Diemant, T.; Zhang, H.; Hoefling, A.; Behm, R. J.; Tübke, J.; Varzi, A.; Passerini, S. Revisiting the Electrochemical Lithiation Mechanism of Aluminum and the Role of Li-rich Phases (Li 1+ x Al) on Capacity Fading. ChemSusChem 2019, 12, 26092619.

(28) Aurbach, D.; Zinigrad, E.; Cohen, Y.; Teller, H. A Short Review of Failure Mechanisms of Lithium Metal and Lithiated Graphite Anodes in Liquid Electrolyte Solutions. Solid State Ionics 2002, 148, 405-416.

(29) Kim, W.-S.; Yoon, W.-Y. Observation of Dendritic Growth on Li Powder Anode using Optical Cell. Electrochim. Acta 2004, 50, 541-545.

(30) Kwon, C. W.; Cheon, S. E.; Song, J. M.; Kim, H. T.; Kim, K. B.; Shin, C. B.; Kim, S. W. Characteristics of a Lithium-Polymer Battery based on a Lithium Powder Anode. J. Power Sources 2001, 93, 145150.

(31) Xu, C.; Sun, B.; Gustafsson, T.; Edström, K.; Brandell, D.; Hahlin, M. Interface Layer Formation in Solid Polymer Electrolyte Lithium Batteries: An XPS Study. J. Mater. Chem. A 2014, 2, 72567264.

(32) Zhao, J.; Gorbatovski, G.; Oll, O.; Thomberg, T.; Lust, E. Effect of Alkali and Halide Ion Doping on the Energy Storage Characteristics of Ionic Liquid Based Supercapacitors. Electrochim. Acta 2019, $319,82-87$. 
(33) Monticelli, S.; Castoldi, L.; Murgia, I.; Senatore, R.; Mazzeo, E.; Wackerlig, J.; Urban, E.; Langer, T.; Pace, V. Recent Advancements on the Use of 2-Methyltetrahydrofuran in Organometallic Chemistry. Monatsh. Chem. 2017, 148, 37-48.

(34) An, S. J.; Li, J.; Daniel, C.; Mohanty, D.; Nagpure, S.; Wood, D. L., III The State of Understanding of the Lithium-Ion-Battery Graphite Solid Electrolyte Interphase (SEI) and its Relationship to Formation Cycling. Carbon 2016, 105, 52-76. 